\title{
BMJ Open Cost-effectiveness analysis of 3 months of weekly rifapentine and isoniazid compared to isoniazid monotherapy in a Canadian arctic setting
}

Christopher Pease (D) , ${ }^{1,2}$ Gonzalo Alvarez, ${ }^{1,2}$ Ranjeeta Mallick, ${ }^{2}$ Mike Patterson, ${ }^{3}$ Sandy Finn, ${ }^{3}$ Yahya Habis, ${ }^{4}$ Kevin Schwartzman (i) , ${ }^{5,6}$ Elaine Kilabuk, ${ }^{7}$ Sunita Mulpuru, ${ }^{1,2}$ Alice Zwerling ${ }^{8}$

To cite: Pease C, Alvarez G, Mallick $\mathrm{R}$, et al. Costeffectiveness analysis of 3 months of weekly rifapentine and isoniazid compared to isoniazid monotherapy in a Canadian arctic setting. BMJ Open 2021;11:e047514. doi:10.1136/ bmjopen-2020-047514

- Prepublication history and additional supplemental material for this paper are available online. To view these files, please visit the journal online (http://dx.doi.org/10.1136/ bmjopen-2020-047514).

Received 30 November 2020 Revised 01 April 2021 Accepted 14 April 2021
Check for updates

(C) Author(s) (or their employer(s)) 2021. Re-use permitted under CC BY-NC. No commercial re-use. See rights and permissions. Published by BMJ.

For numbered affiliations see end of article.

Correspondence to Dr Christopher Pease; Cpease@toh.ca

\section{ABSTRACT}

Objective To assess the cost effectiveness of once weekly rifapentine and isoniazid for 12 weeks (3HP) to the current standard care for latent tuberculosis (TB) infection (LTBI) in Iqaluit, Nunavut.

Design A cost-effectiveness analysis using a Markov model reflecting local practices for LTBI treatment.

Setting A remote Canadian arctic community with a high incidence of TB.

Participants Hypothetical patients with LTBI. Interventions The cost effectiveness of $3 \mathrm{HP}$ was compared with the existing standard of care in the study region which consists of 9 months of twice weekly isoniazid (9H) given by directly observed therapy. Outcome measures Effectiveness was measured in quality-adjusted life years (QALYs) with model parameters were derived from historical programmatic data, a local implementation study of 3HP and published literature. Costs from the perspective of the Nunavut healthcare system were measured in 2019 US dollars and were obtained primarily from local, empirically collected data. Secondary health outcomes included estimated TB cases and TB deaths averted using 3HP versus $9 \mathrm{H}$. One way and probabilistic sensitivity analyses were performed.

Results The $3 \mathrm{HP}$ regimen was dominant over $9 \mathrm{H}$ : costs were lower (US\$628 vs US\$924/person) and health outcomes slightly improved (20.14 vs 20.13 QALYs/ person). In comparison to $9 \mathrm{H}, 3 \mathrm{HP}$ treatment resulted in fewer TB cases ( 27.89 vs $30.16 / 1000$ persons) and TB deaths ( 2.29 vs $2.48 / 1000$ persons). 3HP completion, initiation and risk of fatal adverse events were the primary drivers of cost effectiveness.

Conclusion In a remote Canadian arctic setting, using 3HP instead of $9 \mathrm{H}$ for LTBI treatment may result in cost savings and similar or improved health outcomes.

\section{INTRODUCTION}

Canadian Inuit face high rates of tuberculosis (TB) despite Canada's low overall incidence of TB disease. In 2017, the incidence of active TB among Inuit was 205.8/100 000 compared
Strengths and limitations of this study

- This cost-effectiveness analysis of weekly rifapentine and isoniazid focuses on a remote, high tuberculosis (TB) incidence setting.

- This is the first cost-effectiveness analysis of this treatment in Canada and the first in an Arctic region anywhere in the world.

- Local data were used to obtain most key costs and epidemiological parameters.

- The impact of treatment for latent TB infection on TB transmission was not accounted for in this study.

- Although direct costs of diagnosis and treatment were included in this study, additional costs to patients such as lost wages were not included.

with only 0.5/100 000 among Canadian-born non-indigenous people. ${ }^{1}$

The Government of Canada and Inuit Tapariit Kanatami (Inuit National Organisation) announced goals to eliminate TB across Inuit Nunangat (Inuit homeland) by $2030 .{ }^{2}$ However, challenges persist since Inuit in Arctic communities face geographic isolation and difficult climatic conditions resulting in high costs and limited availability of human and material resources. ${ }^{3}$

Treatment of latent TB infection (LTBI) is critical to achieving TB elimination ${ }^{45}$ and reduces future risk of developing active $\mathrm{TB}$ by over $90 \%{ }^{6}$ but is hindered by lengthy treatment, traditionally involving 9 months of twice weekly isoniazid $(9 \mathrm{H})$. Recently, regimens with a shorter duration have been developed, including once weekly rifapentine and isoniazid for 12 weeks (3HP). In a large randomised controlled trial and subsequent meta-analysis, 3HP demonstrated comparable efficacy, higher completion rates and similar safety profiles to $9 \mathrm{H}^{7-9}$. Although not approved in Canada 
for general use, rifapentine can be obtained under urgent public health need criteria. ${ }^{10}$

Shorter LTBI treatments are of particular interest in the Inuit Nunangat because all LTBI treatment in this region is given in person by directly observed therapy (DOT). This is especially relevant in light of the COVID-19 pandemic since minimising such interactions could reduce opportunities for COVID-19 transmission as well as conserving supplies of personal protective equipment.

Our group recently conducted an implementation study of 3HP for LTBI treatment in Iqaluit, Nunavut. We demonstrated the feasibility of implementing 3HP and found increased (non-statistically significant) completion rates compared with historical $9 \mathrm{H}$ data. ${ }^{11}$

While studies have found 3HP to be cost effective in American, Taiwanese and other settings, ${ }^{12-16}$ no data on 3HP cost effectiveness in Canadian or Arctic settings exist. Unique challenges delivering healthcare in this remote region make generalisations from other settings difficult. An understanding of the cost effectiveness of 3HP in Nunavut would provide critical evidence to support decision-makers across the Inuit Nunangat in allocating healthcare resources efficiently.

The objective of this work was to assess the cost effectiveness of 3HP for the treatment of LTBI in comparison to $9 \mathrm{H}$ in Iqaluit, Nunavut, over a 30 -year time horizon.

\section{METHODS}

\section{Study setting}

Iqaluit is the capital of Nunavut (7740 residents, $55.1 \%$ of whom identify as Inuit ${ }^{17}$ and its largest community). Throughout most of the year, access is only by air with sea access possible during the brief summer. Between 2010 and 2016, 178 cases of active TB were reported in Iqaluit (median: 26 cases/year, range: $9-50$ cases/year) ${ }^{18}$ representing $36 \%$ of all cases in Nunavut. ${ }^{18}$
Testing and treatment for LTBI and active TB in Iqaluit are coordinated by Iqaluit Public Health. Testing is performed for contacts of active TB cases, employment screening (eg, healthcare workers) and in other high risk individuals. ${ }^{19}$ All persons with a positive tuberculin skin test or interferon gamma release assay are assessed by a physician and may be offered LTBI treatment. Standard LTBI treatment has been of 9 months of twice weekly isoniazid via DOT. ${ }^{19}$

\section{Markov model overview}

A Markov model was developed reflecting local practices for LTBI treatment using TreeAge Pro (V.2019; TreeAge Software, Williamstown, Massachusetts, USA). This was used to assess the cost effectiveness of LTBI treatment with 3HP compared with $9 \mathrm{H}$ treatment. The primary outcome was the incremental cost-effectiveness ratio (ICER). The primary health outcome was quality-adjusted life years (QALYs). Costs were calculated in 2019 US dollars from the perspective of the Nunavut healthcare system. Secondary health outcomes included estimated TB cases and TB deaths averted using $3 \mathrm{HP}$ versus $9 \mathrm{H}$. A simplified schematic of the model structure is shown in figures 1 and 2.

The target model population included all persons with LTBI who were offered treatment. A mean age of 25 years was assumed based on local historical data (Iqaluit LTBI programme data, 2010-2016, unpublished). A cohort of LTBI patients offered treatment during the first modelled year were followed over a 30-year time horizon to allow sufficient time for reactivation of LTBI. Markov cycle length was 1 year with half cycle correction applied. Future costs and effectiveness were discounted at a rate of $3 \% .^{2021}$

In both $3 \mathrm{HP}$ and $9 \mathrm{H}$ arms, LTBI patients could initiate or decline treatment. Declining treatment resulted in a period of surveillance involving biannual clinical

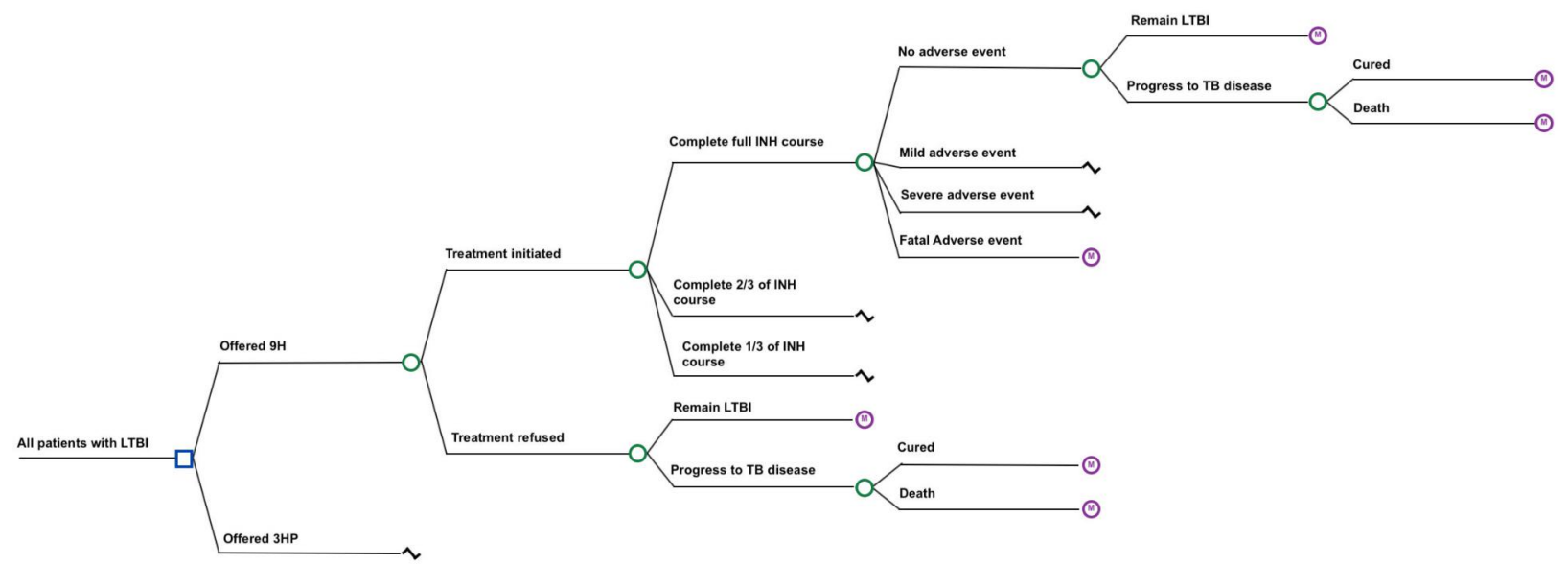

Figure 1 Simplified model decision structure. Two strategies were compared: treating LTBIwith $9 \mathrm{H}$ vs 3HP. Schematically these strategies are separated by a square representing a decisionnode. Green circles represent chance nodes where patients may experience one of severalpossible events shown on subsequent lines. The probabilities of developing each event are listedin Table 1. Jagged lines represent model structure omitted for simplicity. In all cases, thisomitted structure parallels that shown. The "M" symbol represents transition to the Markovportion of the model (shown in Figure 2). 9H = 9 months of twice weekly isoniazid; $3 \mathrm{HP}=12$ weeks of once weekly rifapentine and isoniazid; LTBI = latent tuberculosis infection; TB =tuberculosis. 


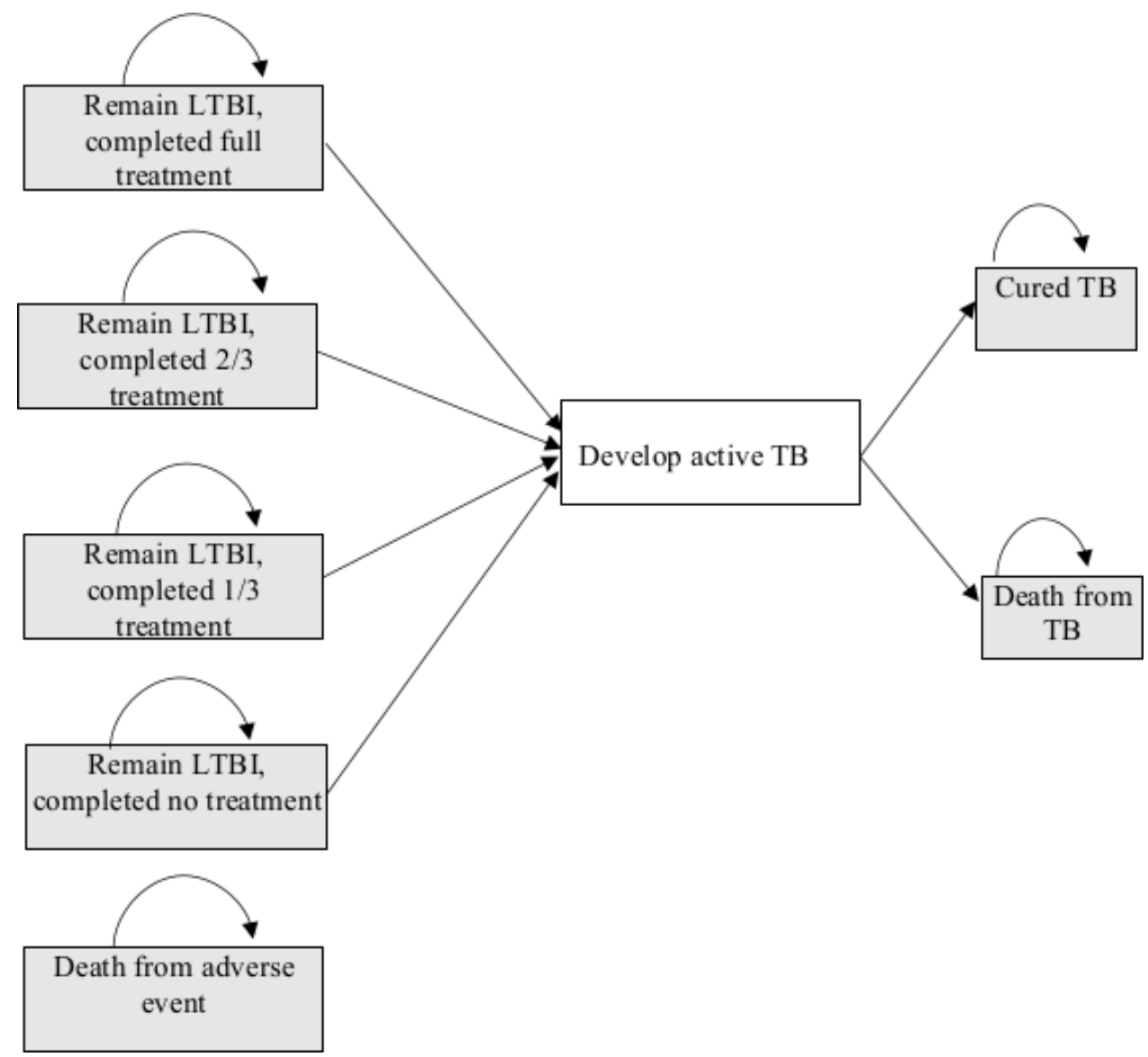

Figure 2 Schematic representation of Markov states. Patients enter this portion of the model in a Markov state (grey boxes) and may remain in that state (curved arrows) or, in some cases, transition to a different one (straight arrows). Patients in all states apart from cured TB disease and death have the possibility to develop active TB with the probability of doing so dependent on the duration of LTBI treatment completed. If active TB develops, it is either cured or results in death within that cycle. LTBI, latent tuberculosis infection; TB, tuberculosis.

assessments, chest X-rays and sputum testing for 2 years among those $\geq 13$ years and quarterly clinical assessments without additional investigations among those $<13$ years. ${ }^{19}$ If initiated, treatment could be partially completed $(<1 / 3$, $1 / 3$ or $2 / 3$ of complete treatment duration) or fully completed (12-week duration for 3HP, 9-month duration for $9 \mathrm{H}$ ). Patients in both arms could experience adverse events (AEs) of varying severity (none, mild, severe and fatal), which might or might not result in stopping treatment. Active TB disease could occur at varying rates depending on LTBI treatment duration. All active TB was assumed to be diagnosed and treated, and patients could either be cured or die.

\section{Key model assumptions}

The rates of treatment initiation, fatal AEs and reduction in LTBI reactivation risk (based on a large non-inferiority trial $^{7}$ ) were assumed to be equal between $3 \mathrm{HP}$ and $9 \mathrm{H}$ in base case analysis, but all variables were varied independently in sensitivity analyses. No fatal AEs related to 3HP have been reported among several randomised trials $^{22}$ yet long-term data comparable to $9 \mathrm{H}$ are not available; therefore, we assumed equal fatal toxicity risk between regimens, consistent with previous costeffectiveness studies. ${ }^{131623}$

The risk of AEs and the reduction in LTBI reactivation risk were assumed to be directly proportional to the treatment duration with no risk of AEs or reduction in reactivation risk among those completing less than one-third of the treatment.

\section{Definitions}

Treatment initiation was defined as taking $\geq 1$ dose of medication. Mild AEs included grade 1-2 events and severe AEs included grade 3-4 events as defined by the Common Terminology Criteria for Adverse Events. ${ }^{24}$

\section{Epidemiologic parameters}

Model epidemiologic parameters are provided in table 1. Where possible, model parameters were based on historical data from Iqaluit and from a recent 3HP implementation study done in Iqaluit. ${ }^{11} 18$

\section{Cost parameters}

The cost parameters were derived from local unit costs with the exception of $\mathrm{TB}$ treatment cost, which was derived from total $\mathrm{TB}$ treatment costs in Iqaluit divided 
Table 1 Epidemiologic parameter estimates

\begin{tabular}{llcl}
\hline Parameter & Base case estimate & Univariable analysis range & Reference(s) \\
\hline Initiation rate & & & Iqaluit LTBI program $^{11} 28$ \\
9H & 0.79 & $0.72-0.80$ & \\
3HP & $0.79^{1}$ & $0.72-0.80^{*}$ &
\end{tabular}

Completion rates

$9 \mathrm{H}$

Probability of stopping isoniazid before 3 months among

0.103

Iqaluit LTBI programme all those who initiated treatment

$\begin{array}{lll}\text { Probability of stopping isoniazid at } 3 \text { months among all } & 0.088 & 0.063-0.122\end{array}$ those who completed at least 3 months of treatment

Probability of stopping isoniazid at 6 months among all $\quad 0.078$ those who completed at least 6 months of treatment

Probability of completing 9 months of treatment among all 0.750 persons who initiated treatment $\dagger$

3HP

\begin{tabular}{lll}
$\begin{array}{l}\text { Probability of stopping } 3 \mathrm{HP} \text { before } 4 \text { weeks among all } \\
\text { those who initiated treatment }\end{array}$ & 0.082 & $0.038-0.168$ \\
$\begin{array}{l}\text { Probability of stopping } 3 \mathrm{HP} \text { at } 4 \text { weeks among all those } \\
\text { who completed at least } 4 \text { weeks of treatment }\end{array}$ & 0.075 & $0.032-0.163$ \\
\hline
\end{tabular}

$\begin{array}{lll}\text { Probability of stopping } 3 \mathrm{HP} \text { at } 8 \text { weeks among all those } 0.032 & 0.009-0.110\end{array}$ who completed at least 8 weeks of treatment

Probability of completing 12 weeks of treatment among all 0.820 persons who initiated treatment†

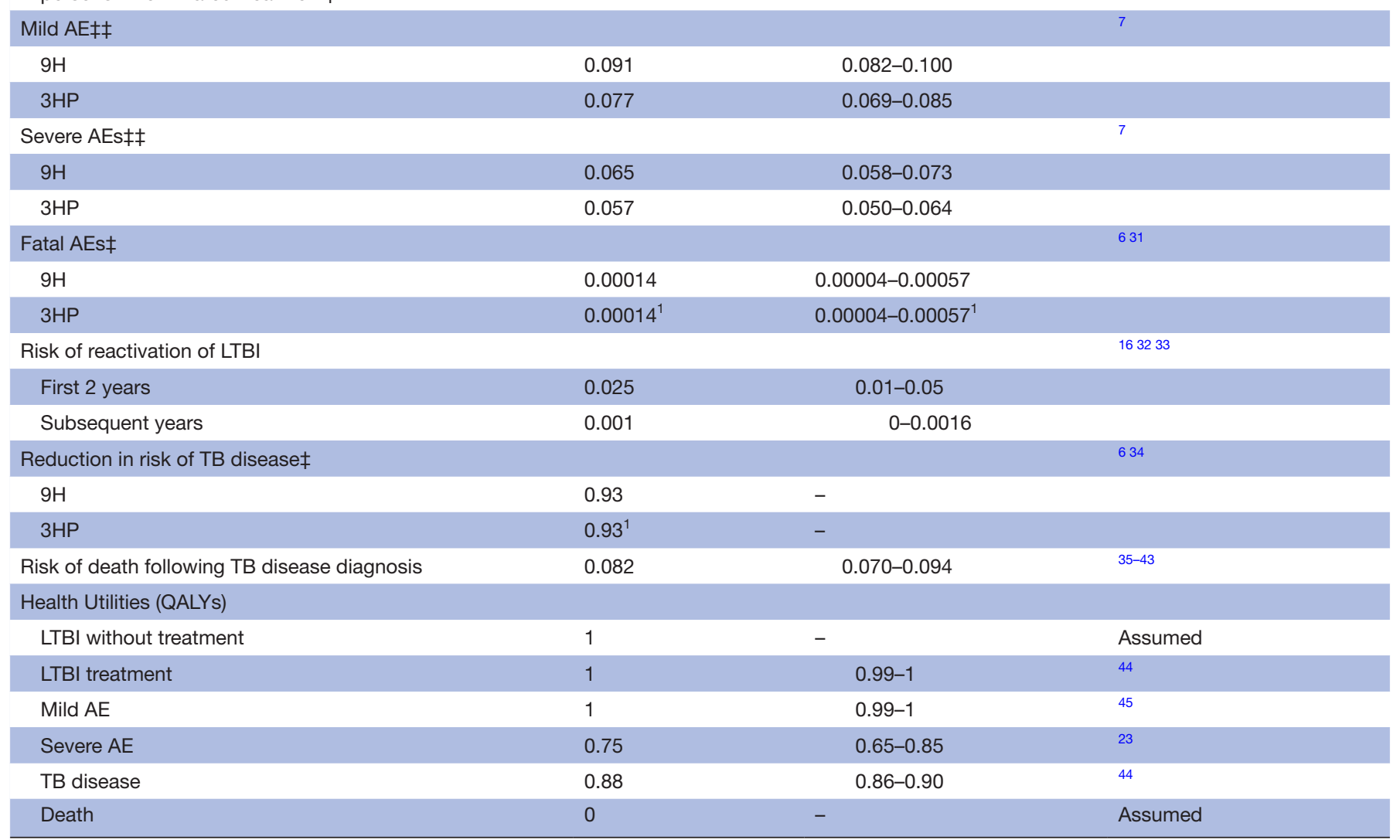

Iqaluit LTBI programme: retrospective data from the Iqaluit LTBI programme, 2010-2016, unpublished.

${ }^{*}$ Assumed identical values for $9 \mathrm{H}$ and $3 \mathrm{HP}$ in base case analysis.

†Overall completion rates among initiators are given for reference. Only the component probabilities provide were used in the model.

tValues for partially completed regimens were interpolated assuming a linear relationship between duration of treatment and parameter values.

AEs, adverse events; 9H, 9 months of twice weekly isoniazid; 3HP, once weekly rifapentine and isoniazid for 12 weeks; LTBI, latent tuberculosis infection; QALYs, quality-adjusted life years; TB, tuberculosis. 
Table 2 Cost parameter estimates. Costs are in 2019 US dollars

\begin{tabular}{|c|c|c|c|}
\hline Parameter & Base case estimate & Univariable analysis range & Reference(s) \\
\hline Complete $9 \mathrm{H}$ treatment & $\$ 806$ & $\$ 489-\$ 1207$ & $\mathrm{IPH}, \mathrm{NMH}^{25}$ \\
\hline Drug costs & $\$ 5$ & & \\
\hline Other clinician costs & $\$ 173$ & & \\
\hline Chest X-ray & $\$ 55$ & & \\
\hline Sputum testing & $\$ 64$ & & \\
\hline \multicolumn{4}{|l|}{ Partial isoniazid treatment } \\
\hline 3 months & $\$ 388$ & $\$ 271-\$ 543$ & $\mathrm{IPH}, \mathrm{NMH}^{25}$ \\
\hline 6 months & $\$ 597$ & $\$ 389-\$ 874$ & $\mathrm{IPH}, \mathrm{NMH}^{25}$ \\
\hline Complete 3HP treatment & $\$ 383$ & $\$ 296-\$ 492$ & $\mathrm{IPH}, \mathrm{NMH}^{25}$ \\
\hline Drug costs & $\$ 87$ & & \\
\hline Sputum testing & $\$ 64$ & & \\
\hline Liver function testing & $\$ 5$ & & \\
\hline \multicolumn{4}{|l|}{ Partial isoniazid+rifapentine treatment } \\
\hline 4 weeks & $\$ 126$ & $\$ 103-\$ 159$ & $\mathrm{IPH}, \mathrm{NMH}^{25}$ \\
\hline 8 weeks & $\$ 194$ & $\$ 151-\$ 253$ & $\mathrm{IPH}, \mathrm{NMH}^{25}$ \\
\hline Mild AE & $\$ 13$ & $\$ 0-\$ 197$ & $\mathrm{IPH}^{13}$ \\
\hline Nursing costs & $\$ 13$ & & \\
\hline Severe AE & $\$ 2584$ & $\$ 1379-\$ 6614$ & $\mathrm{IPH}, \mathrm{NMH}^{1325}$ \\
\hline Hospitalisation in Iqaluit $\times 1.2$ days $^{*}$ & $\$ 2411$ & & \\
\hline Intensive care unit in Ottawa $\times 7$ days & $\$ 24359$ & & \\
\hline Cured TB disease & $\$ 1517$ & $\$ 1214-\$ 28841$ & $\mathrm{IPH}^{25}$ \\
\hline Fatal TB disease & $\$ 66495$ & $\$ 41365-\$ 76635$ & $\mathrm{IPH}^{25} 46$ \\
\hline TB treatment costs $\times 6$ months & $\$ 759$ & & \\
\hline Hospitalisation in Iqaluit $\times 7$ days & $\$ 14059$ & & \\
\hline Medical evacuation & $\$ 19952$ & & \\
\hline Hospitalisation in Ottawa 7 days & $\$ 7366$ & & \\
\hline Intensive care unit in Ottawa $\times 7$ days & $\$ 24359$ & & \\
\hline Surveillance for those $<13$ years old & $\$ 54$ & $\$ 50-\$ 65$ & $\mathrm{IPH}, \mathrm{NMH}$ \\
\hline Nursing costs & $\$ 54$ & & \\
\hline Surveillance for those $\geq 13$ years old & $\$ 531$ & $\$ 431-\$ 638$ & $\mathrm{IPH}, \mathrm{NMH}$ \\
\hline Nursing costs & $\$ 54$ & & \\
\hline Chest X-ray $\times 4$ & $\$ 220$ & & \\
\hline Sputum testing $\times 4$ & $\$ 257$ & & \\
\hline
\end{tabular}

IPH: data from Iqaluit Public Health, 2019, unpublished.

NMH: data from Nunavut Ministry of Health, 2019, unpublished.

*The number of days of hospitalisation was used assuming that, as in Sterling et al, $17 \%$ of these patients would have a grade $4 \mathrm{AE}$ and all those with a grade $4 \mathrm{AE}$ would require 7 days of hospitalisation.

AEs, adverse events; DOT, directly observed therapy; 9H, 9 months of twice weekly isoniazid; 3HP, once weekly rifapentine and isoniazid for 12 weeks. 
by the number of persons treated (table 2). Estimates of personnel time were determined by direct onsite observation of TB activities supplemented by interviews with local personnel. Local unit costs of medications, consumables and salaries were obtained from Iqaluit Public Health and the Government of Nunavut Department of Health. Local unit costs of diagnostics, hospitalisation and medical transport were obtained from published literature. ${ }^{25}$ All costs were adjusted to 2019 Canadian dollars using the Canadian Consumer Price Index,${ }^{26}$ then converted to US dollars using the average 2019 exchange rate. ${ }^{27}$

\section{Sensitivity and scenario analyses}

One-way (univariable) sensitivity analyses were conducted across all model parameters, time horizon (10-50 years) and discounting rate $(0 \%-5 \%)$. Probabilistic sensitivity analysis was also performed by specifying underlying distributions for model parameters and using Monte Carlo simulation with 10000 iterations to generate $95 \%$ uncertainty ranges (95\% UR) around model outputs. Probability distributions for model parameters are provided in online supplemental e-Appendix. Finally, scenario analyses were performed to more comprehensively explore the impact of select model parameters. Scenario analyses included variation in the initiation and overall completion rates of $3 \mathrm{HP} \pm 10 \%$ versus 9 hours, increasing risk of $3 \mathrm{HP}$ severe AEs to twice that of $9 \mathrm{H}$ and varying annual LTBI reactivation from $0.1 \%$ to $10 \%$ for the first 2 years. The impact on cost of self-administration of both regimens was also assessed.

\section{Budget impact analysis}

A budget impact analysis was performed over 1-year, 2-year and 5-year horizons estimating the total difference in healthcare cost of $3 \mathrm{HP}$ compared with $9 \mathrm{H}$. Average per patient incremental costs for the relevant year(s) was determined from the model and multiplied by the average annual number of patients initiating LTBI treatment in Iqaluit between 2010 and 2016, which was 69 (Iqaluit LTBI programme data, 2010-2016, unpublished).

\section{Patient and public involvement}

Patient input informed the development of the research question by expressing a desire for implementation of a feasibility effective but short treatment regimen for LTBI. Patients were not directly involved in the design or conduct of the study. Key local stakeholders have been informed of the study results through a series of in-person and teleconferenced meetings. A plain language summary of the study will be made available to the public via the Taima $\mathrm{TB}$ research group website.

\section{RESULTS}

3HP dominated $9 \mathrm{H}$ with cost savings ( $\$ 628$ vs $\$ 924$ per person) and slight improvement in health outcome (20.14 vs 20.13 QALYs per person) (table 3). This resulted in a negative ICER.
Table 3 Base case cost-effectiveness model outcomes

\begin{tabular}{lll}
\hline & 9H & 3HP \\
\hline Clinical outcomes & & \\
\hline Overall effectiveness (QALYs) & 20.13 & 20.14 \\
\hline TB cases per 1000 LTBI cases & 30.16 & 27.89 \\
\hline TB deaths per 1000 LTBI cases & 2.48 & 2.29 \\
\hline Cost outcomes (2019 US\$) & & \\
$\quad$ Total cost & $\$ 924$ & $\$ 628$ \\
\hline Costs of LTBI treatment & $\$ 535$ & $\$ 260$ \\
$\quad$ Costs of AEs & $\$ 116$ & $\$ 108$ \\
\hline $\begin{array}{l}\text { Costs of TB disease treatment } \\
\text { Surveillance costs }\end{array}$ & $\$ 182$ & $\$ 168$ \\
\hline
\end{tabular}

Costs are in 2019 US dollars.

AEs, adverse events; $9 \mathrm{H}, 9$ months of twice weekly isoniazid; $3 \mathrm{HP}$, once weekly rifapentine and isoniazid for 12 weeks; LTBI, latent tuberculosis infection; QALY, quality-adjusted life years; TB, tuberculosis.

Cost savings were driven by fewer visits required to deliver 3HP (12 doses) compared with 9H (78 doses). Cost savings also resulted from fewer AEs with $3 \mathrm{HP}$ and fewer TB cases (27.89 vs 30.16 per 1000 LTBI cases) due to its higher completion rate (table 3 ). The improvement in health outcomes was driven primarily by higher completion rates for $3 \mathrm{HP}$, resulting in fewer TB cases (noted above) and TB deaths (2.29 vs 2.48 per 1000 LTBI) in the 3HP arm.

In budget impact analysis, 3HP resulted in cumulative savings of $\$ 19888$ over 1 year, $\$ 40122$ over 2 years and $\$ 100904$ over 5 years compared with 9 hours, assuming a constant annual rate of LTBI treatment initiation.

\section{Sensitivity analyses}

In one-way sensitivity analyses, the model was most sensitive to variables related to $3 \mathrm{HP}$ completion and initiation and fatal AEs during 3HP treatment. These were the only variables with the potential to result in worsened health outcomes in the 3HP arm compared with 9H (online supplemental e-appendix, e-figures 1 and 2). $3 \mathrm{HP}$ remained dominant despite varying discounting rate (0\%-5\% per year), time horizon (10-50 years) and all other variables (online supplemental e-appendix, e-tables 3 and 4).

In the probabilistic sensitivity analysis, the probability of $3 \mathrm{HP}$ being dominant over $9 \mathrm{H}$ was $94.1 \%$ (figure 3 ). The median cost per LTBI case was $\$ 614$ (95\% UR: $\$ 487$ $\$ 1005)$ for 3HP versus \$888 (95\% UR: \$662-\$1335) for $9 \mathrm{H}$ and the median QALYs per LTBI case were 20.13 (20.10-20.16) for 3HP versus 20.13 (20.09-20.15) for $9 \mathrm{H}$. The probability of $3 \mathrm{HP}$ being less costly than $9 \mathrm{H}$ was $99.9 \%$ and the probability of 3HP being more effective than $9 \mathrm{H}$ was $94.2 \%$.

\section{Scenario analyses}

When 3HP initiation and completion rates were varied $\pm 10 \%$, 3HP remained cost saving (online supplemental 


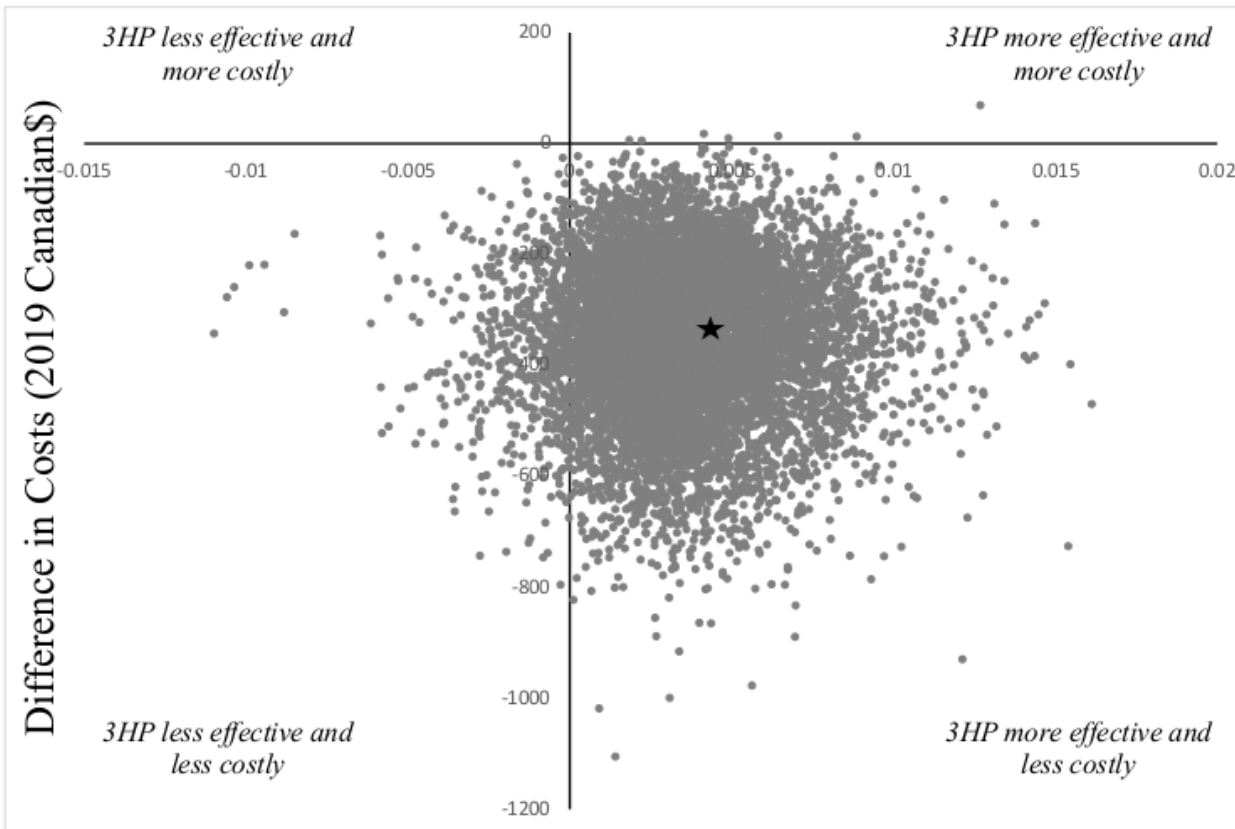

Difference in Effectiveness (QALYs)

Figure 3 Cost-effectiveness plane showing the differences in costs and QALYs of using 3HP compared with using 9H from 10000 simulations. The star represents the base case scenario. 3HP, once weekly rifapentine and isoniazid for 12 weeks; $9 \mathrm{H}, 9$ months of twice weekly isoniazid; QALYs, quality-adjusted life years.

e-appendix, e-table 5a), but 3HP was no longer dominant over $9 \mathrm{H}$ when the $3 \mathrm{HP}$ initiation rate was $<73.4 \%$ (vs $79.0 \%$ for $9 \mathrm{H}$ ) and when the $3 \mathrm{HP}$ completion rate was $<74.4 \%$ (vs $75 \%$ for $9 \mathrm{H}$ and $82.0 \%$ in the base case analysis) due to worsened health outcome (figure $4 \mathrm{~A}$ ). If the severe $\mathrm{AE}$ rate of $3 \mathrm{HP}$ increased to $>7.4 \%$ (5.6\% in base case analysis), 3HP also resulted in worsened health outcome compared with $9 \mathrm{H}$ (figure $4 \mathrm{~B}$ ) but remained cost saving (online supplemental e-appendix, e-table 5b). $3 \mathrm{HP}$ remained dominant over $9 \mathrm{H}$ across a broad range of LTBI reactivation rates (figure $4 \mathrm{~b}$ and c; online supplemental e-appendix, e-tables $5 \mathrm{~b}$ and $\mathrm{c}$ ). If both $3 \mathrm{HP}$ and $9 \mathrm{H}$ were self-administered, 3HP remained dominant (online supplemental e-appendix, e-table 6). Cost savings were reduced, but $9 \mathrm{H}$ cost remained above $3 \mathrm{HP}$ because higher medication cost was offset by additional clinical visits during the longer $9 \mathrm{H}$ regimen and slightly higher costs from more active TB cases and AEs in the $9 \mathrm{H}$ arm.

\section{DISCUSSION}

Using a Markov model of LTBI treatment in a Canadian Arctic setting, our study suggests that the 3HP regimen will be superior to $9 \mathrm{H}$ (both cost saving and slightly more effective) across a range of assumptions. Both TB cases and TB deaths were projected to be lower with the use of this regimen.

The finding of cost savings with the $3 \mathrm{HP}$ regimen was very robust across a broad range of sensitivity and scenario analyses. As such, it is highly likely that implementation of $3 \mathrm{HP}$ would result in reduced costs for the Iqaluit TB programme and likely other similar settings as well. In budget impact analysis, the total savings were estimated at over \$19000 annually assuming that LTBI diagnosis and treatment continue at a similar pace. The primary driver of 3HP cost savings was the lower number of DOT visits due to shorter treatment duration. Additional savings accrued from fewer AEs and fewer active TB cases in 3HP arm meaning that modest cost savings were maintained even when both regimens were self-administered.

While $3 \mathrm{HP}$ results in a slightly improved health outcome compared with $9 \mathrm{H}$ in most sensitivity analyses, extreme values of 3 key parameters (3HP initiation $<73.4 \%$, 3HP completion $<74.4 \%$ and $3 \mathrm{HP}$ fatal $\mathrm{AE}$ rate $>0.00042$ ) resulted in 3HP producing a worsened health outcome compared with $9 \mathrm{H}$. A substantial decrease in 3HP initiation compared with $9 \mathrm{H}$ was modelled to evaluate the robustness of our findings but is unlikely to occur: the 3HP initiation rate was similar to the historical rate during a recent community rollout in Nunavut $(80 \%$ with $3 \mathrm{HP}$ vs $79 \%$ historically) ${ }^{11}$ and a recent study in an urban setting found stable initiation rates following the introduction of $3 \mathrm{HP}$ (78\% with $3 \mathrm{HP}$ vs $79 \%$ historically). ${ }^{28}$

Another key influence on the relative effectiveness of the two regimens was the $3 \mathrm{HP}$ completion rate. When $3 \mathrm{HP}$ completion dropped below $74.4 \%$ (vs $82 \%$ in base case), 3HP resulted in a worsened health outcome compared with $9 \mathrm{H}$. Previous studies have demonstrated consistently higher completion for $3 \mathrm{HP}$ than $9 \mathrm{H}$ suggesting such a scenario is unlikely. ${ }^{78}$ However, unlike many settings, $9 \mathrm{H}$ is delivered via DOT in Iqaluit resulting in higher 
A Impact of variation in $3 \mathrm{HP}$ initiation rate and $3 \mathrm{HP}$ completion rate to $10 \%$ above and below those of $9 \mathrm{H}$.

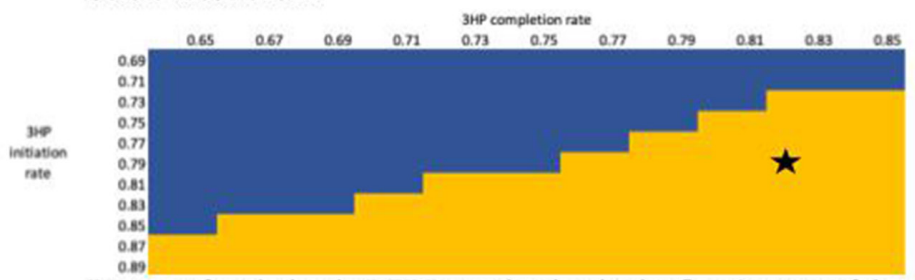

B Impact of variation in LTBI reactivation in the first 2 years of the model and the rate of severe adverse events while taking $3 \mathrm{HP}$

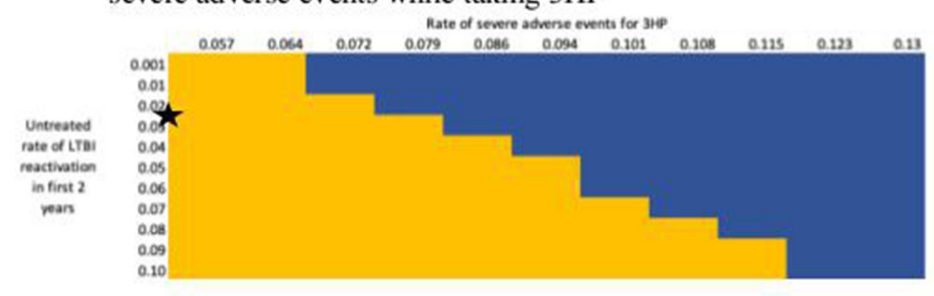

C Impact of variation in LTBI reactivation in the first 2 years of the model and the $3 \mathrm{HP}$ completion rate.

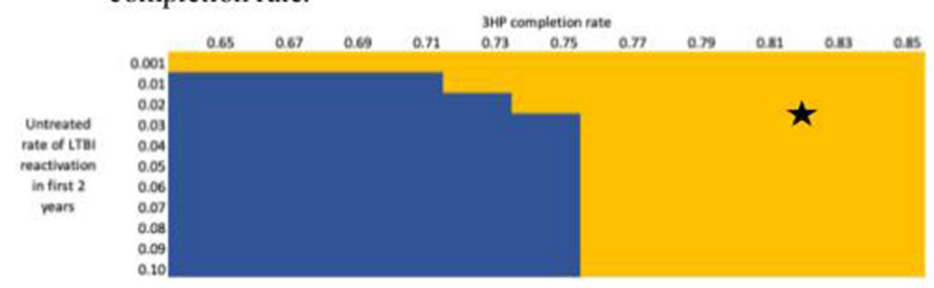

19e less effective than $9 H$

Figure 4 Influence on the relative effectiveness of $3 \mathrm{HP}$ versus $9 \mathrm{H}$ of variation in a variety of parameters to extreme values. Blue areas indicate that $3 \mathrm{HP}$ is less effective than $9 \mathrm{H}$, while orange areas indicate that $3 \mathrm{HP}$ is more effective than $9 \mathrm{H}$. The stars represent the values in the base case. (A) Impact of variation in 3HP initiation rate and $3 \mathrm{HP}$ completion rate to $10 \%$ above and below those of $9 \mathrm{H}$. (B) Impact of variation in LTBI reactivation in the first 2 years of the model and the rate of severe adverse events while taking 3HP. (C) Impact of variation in LTBI reactivation in the first 2 years of the model and the 3HP completion rate. $3 \mathrm{HP}$, once weekly rifapentine and isoniazid for 12 weeks; $9 \mathrm{H}, 9$ months of twice weekly isoniazid; LTBI, latent tuberculosis infection.

9H completion rates compared with other settings. ${ }^{18}$ Despite this, within the recent $3 \mathrm{HP}$ implementation trial in Iqaluit, there was a non-statistically significant trend to improved completion among those taking $3 \mathrm{HP}$ versus historical rates $(82 \%$ vs $73 \%) .{ }^{11}$ Furthermore, even if 3HP completion was modestly overestimated in our model, $3 \mathrm{HP}$ would remain cost saving.

As mentioned, given the absence of reported fatal AEs associated with $3 \mathrm{HP},{ }^{22}$ the assumption of equal risk of fatal toxicity between $3 \mathrm{HP}$ and $9 \mathrm{H}$ is likely quite conservative. In sensitivity analysis, only when risk of fatal AEs associated with $3 \mathrm{HP}$ was 3.5 times higher than $9 \mathrm{H}(0.00042$ vs 0.00012 ) was $3 \mathrm{HP}$ associated with a worse health outcome compared with $9 \mathrm{H}$. Such an increase seems unlikely.

The most recent Canadian Tuberculosis Standards note concern regarding potential AEs associated with $3 \mathrm{HP}^{29}$ In scenario analysis, the rate of severe AEs related to $3 \mathrm{HP}$ would need to rise to $7.4 \%$ for $3 \mathrm{HP}$ to be associated with a worse health outcome than $9 \mathrm{H}$. This is substantially higher than the $5.6 \%$ observed in a large clinical trial of 3HP. ${ }^{7}$
While the current study focused on $9 \mathrm{H}$ and $3 \mathrm{HP}$, several other LTBI treatment regimens are used in other settings. ${ }^{29}$ This includes rifampin given daily for 4 months (4R), which has recently been shown to be non-inferior to 9 months of daily isoniazid in a large randomised controlled trial. ${ }^{30} 4 \mathrm{R}$ was not considered in the current study since all LTBI treatment in Nunavut is given by DOT and use of $4 \mathrm{R}$ would require an increase in the number of DOT visits from 78 doses with the current standard of twice weekly isoniazid to 120 doses with $4 \mathrm{R}$. This was not felt to be feasible given the limited resources of the local TB programme.

This study has a number of strengths. First, it is the first study of cost effectiveness of 3HP in Canada and the first in an Arctic region. This regimen has been of particular interest since the onset of the COVID-19 pandemic since it requires the fewest doses of any currently recommended LTBI treatment. ${ }^{29}$ Because all LTBI treatment in Nunavut is given in person by DOT, reducing LTBI treatment doses minimises opportunities for viral transmission and conserves personal protective equipment. Second, 
local data were used to obtain most key costs and epidemiologic parameters.

Study limitations include an inability to account for TB transmission, which would have greatly increased model complexity. However, including transmission in the model would likely have favoured 3HP since this strategy resulted in fewer active TB cases and thus 3HP would be expected to remain the dominant strategy. Second, societal costs, including costs borne by patients, were not included. Inclusion would again likely favour $3 \mathrm{HP}$ given its shorter duration and lower burden of AEs compared with $9 \mathrm{H}$. Third, the costs associated with the implementation and scale-up of 3HP such as additional staff training were not included. Fourth, we did not include the probability of death from causes other than TB and treatmentrelated AEs in our model. However, this factor would not differ between the two treatment arms in our study and thus would not be expected to have an important impact on incremental cost or effectiveness. Finally, reinfection with TB was not modelled but would be unlikely to substantially change the relative standing of $3 \mathrm{HP}$ and $9 \mathrm{H}$ since reinfection risk is not related to previous treatment regimen.

\section{CONCLUSION}

The findings of the present study suggest that in a remote Canadian arctic setting, 3HP is likely to offer cost savings and slightly improved health outcomes compared with 9 hour driven by higher anticipated completion rates. This would support the implementation of 3HP as standard therapy for LTBI treatment in Nunavut and other similar settings.

\section{Author affiliations \\ ${ }^{1}$ Division of Respirology, Ottawa Hospital General Campus, Ottawa, Ontario, Canada \\ ${ }^{2}$ Ottawa Hospital Research Institute, Ottawa, Ontario, Canada \\ ${ }^{3}$ Department of Health, Government of Nunavut, Iqaluit, Nunavut, Canada \\ ${ }^{4}$ Deparment of Medicine, King Abdulaziz University, Jeddah, Saudi Arabia \\ ${ }^{5}$ Montreal Chest Institute, Montreal, Quebec, Canada \\ ${ }^{6}$ Department of Medicine, McGill University, Montreal, Quebec, Canada \\ ${ }^{7}$ Department of Internal Medicine, Faculty of Medicine, University of Ottawa, Ottawa, Ontario, Canada \\ ${ }^{8}$ School of Epidemiology and Public Health, University of Ottawa, Ottawa, Ontario, Canada}

Contributors GA, MP, SF and AZ conceived the study. The study was designed by AZ, CP and GA. SF and EK collected data. Data analysis was performed by CP with assistance from $A Z$. $C P, A Z$ and $G A$ interpreted the data with assistance from $K S$, RM, SM, MP, SF, EK and YH. CP drafted the initial manuscript, which was revised and approved by all authors. CP takes responsibility for the integrity of the data and accuracy of the data analysis.

Funding The study was funded by the Public Health Agency of Canada.

Competing interests None declared.

Patient consent for publication Not required.

Ethics approval Research ethics board approval was not required for this study since it did not involve the collection of patient data.

Provenance and peer review Not commissioned; externally peer reviewed.

Data availability statement All data relevant to the study are included in the article or uploaded as supplementary information.
Supplemental material This content has been supplied by the author(s). It has not been vetted by BMJ Publishing Group Limited (BMJ) and may not have been peer-reviewed. Any opinions or recommendations discussed are solely those of the author(s) and are not endorsed by BMJ. BMJ disclaims all liability and responsibility arising from any reliance placed on the content. Where the content includes any translated material, BMJ does not warrant the accuracy and reliability of the translations (including but not limited to local regulations, clinical guidelines, terminology, drug names and drug dosages), and is not responsible for any error and/or omissions arising from translation and adaptation or otherwise.

Open access This is an open access article distributed in accordance with the Creative Commons Attribution Non Commercial (CC BY-NC 4.0) license, which permits others to distribute, remix, adapt, build upon this work non-commercially, and license their derivative works on different terms, provided the original work is properly cited, appropriate credit is given, any changes made indicated, and the use is non-commercial. See: http://creativecommons.org/licenses/by-nc/4.0/.

\section{ORCID iDs}

Christopher Pease http://orcid.org/0000-0002-7244-7413

Kevin Schwartzman http://orcid.org/0000-0002-3354-1159

\section{REFERENCES}

1 LaFreniere M, Hussain H, He N, et al. Tuberculosis in Canada: 2017. Can Commun Dis Rep 2019;45:68-74.

2 Canada IS, Canada IS. Eliminating Tuberculosis across Inuit Nunangat by 2030; at least a $50 \%$ reduction by 2025 [Internet]. gcnws, 2018. Available: https://www.canada.ca/en/indigenousservices-canada/news/2018/03/eliminating-tuberculosis-acrossinuit-nunangat-by-2030-at-least-a-50-reduction-by-2025.html [Accessed 18 Jun 2018].

3 Patterson M, Flinn S, Barker K. Addressing tuberculosis among Inuit in Canada. Can Commun Dis Rep 2018;44:82-5.

4 Inuit Tuberculosis Elimination Framework [Internet]. Inuit Tapiriit Kanatami, 2018. Available: https://www.itk.ca/wp-content/uploads/ 2018/12/FINAL-ElectronicEN-Inuit-TB-Elimination-Framework.pdf

5 Dye C, Glaziou P, Floyd K, et al. Prospects for tuberculosis elimination. Annu Rev Public Health 2013;34:271-86.

6 Efficacy of various durations of isoniazid preventive therapy for tuberculosis: five years of follow-up in the IUAT trial. International Union against tuberculosis Committee on prophylaxis. Bull World Health Organ 1982;60:555-64.

7 Sterling TR, Villarino ME, Borisov AS, et al. Three months of rifapentine and isoniazid for latent tuberculosis infection. $N$ Engl $J$ Med 2011;365:2155-66.

8 Pease C, Hutton B, Yazdi F, et al. Efficacy and completion rates of rifapentine and isoniazid $(3 \mathrm{Hp})$ compared to other treatment regimens for latent tuberculosis infection: a systematic review with network meta-analyses. BMC Infect Dis 2017;17:265.

9 Pease C, Hutton B, Yazdi F, et al. A systematic review of adverse events of rifapentine and isoniazid compared to other treatments for latent tuberculosis infection. Pharmacoepidemiol Drug Saf 2018;27:557-66.

10 List of Drugs for an Urgent Public Health Need [Internet]. Public health agency of Canada. Available: https://www.canada.ca/en/ health-canada/services/drugs-health-products/access-drugsexceptional-circumstances/list-drugs-urgent-public-health-need.html [Accessed cited 2019 Nov 7].

11 Alvarez GG, Van Dyk D, Mallick R, et al. The implementation of rifapentine and isoniazid $(3 \mathrm{Hp})$ in two remote Arctic communities with a predominantly Inuit population, the Taima TB $3 \mathrm{Hp}$ study. Int $J$ Circumpolar Health 2020;79:1758501.

12 Kowada A. Cost effectiveness of interferon-gamma release assay for tuberculosis screening using three months of rifapentine and isoniazid among long-term expatriates from low to high incidence countries. Travel Med Infect Dis 2016;14:489-98.

13 Shepardson D, Marks SM, Chesson H, et al. Cost-Effectiveness of a 12-dose regimen for treating latent tuberculous infection in the United States. Int J Tuberc Lung Dis 2013;17:1531-7.

14 Huang Y-W, Yang S-F, Yeh Y-P, et al. Impacts of 12-dose regimen for latent tuberculosis infection: treatment completion rate and costeffectiveness in Taiwan. Medicine 2016;95:e4126.

15 Johnson KT, Churchyard GJ, Sohn H, et al. Cost-Effectiveness of preventive therapy for tuberculosis with isoniazid and rifapentine versus isoniazid alone in high-burden settings. Clin Infect Dis 2018;67:1072-8.

16 Doan TN, Fox GJ, Meehan MT, et al. Cost-effectiveness of 3 months of weekly rifapentine and isoniazid compared with other standard 
treatment regimens for latent tuberculosis infection: a decision analysis study. J Antimicrob Chemother 2019;74:218-27.

17 Government of Canada SC. Census Profile, 2016 Census - Nunavut [Territory] and Iqaluit, City [Census subdivision], Nunavut [Internet], 2017. Available: http://www12.statcan.gc.ca/census-recensement/ 2016/dp-pd/prof/details/Page.cfm?Lang=E\&Geo1=PR\&Code1=62\& Geo2=CSD\&Code2 $=6204003 \& D a t a=$ Count\&SearchText $=$ Nunavut $\&$ SearchType=Begins\&SearchPR=01\&B1=All\&GeoLevel=PR\& GeoCode=62 [Accessed 18 Jun 2018].

18 Pease C, Zwerling A, Mallick R, et al. The latent tuberculosis infection cascade of care in lqaluit, Nunavut, 2012-2016. BMC Infect Dis 2019;19:890.

19 Nunavut tuberculosis manual. government of Nunavut 2018.

20 Sanders GD, Neumann PJ, Basu A, et al. Recommendations for conduct, methodological practices, and reporting of costeffectiveness analyses: second panel on cost-effectiveness in health and medicine. JAMA 2016;316:1093-103.

21 Edejer T, Baltussen R, Adam T, et al. Who guide to cost-effectiveness analysis. World Health Organization, 2003.

22 Pease $\mathrm{C}$, Hutton B, Yazdi F, et al. A systematic review of adverse events of rifapentine and isoniazid compared to other treatments for latent tuberculosis infection. Pharmacoepidemiol Drug Saf 2018;27:557-66.

23 Holland DP, Sanders GD, Hamilton CD, et al. Costs and costeffectiveness of four treatment regimens for latent tuberculosis infection. Am J Respir Crit Care Med 2009;179:1055-60.

24 US Department of Health and Human Services. Common terminology criteria for adverse events (CTCAE), version 5. National Institutes of health National cancer Institute 2017.

25 Sugarman J, Alvarez GG, Schwartzman K, et al. Sputum induction for tuberculosis diagnosis in an Arctic setting: a cost comparison. Int J Tuberc Lung Dis 2014;18:1223-30.

26 Consumer Price Index. annual average, not seasonally adjusted [Internet]. Statistics Canada. Available: https://www150.statcan.gc. $\mathrm{ca} / \mathrm{t} 1 / \mathrm{tb} / 1 / \mathrm{en} / \mathrm{tv}$.action?pid=1810000501

27 International Monetary Fund. IMF exchange rates database.

28 Stennis NL, Burzynski JN, Herbert C, et al. Treatment for tuberculosis infection with 3 months of isoniazid and rifapentine in New York City health department clinics. Clin Infect Dis 2016;62:53-9.

29 Long R. Canada PHA of. Canadian tuberculosis standards 7th edition, 2014. Available: https://www.canada.ca/en/public-health/ services/infectious-diseases/canadian-tuberculosis-standards-7thedition.html [Accessed 19 Nov 2017].
30 Menzies D, Adjobimey M, Ruslami R, et al. Four months of rifampin or nine months of isoniazid for latent tuberculosis in adults. $N$ Engl $J$ Med 2018;379:440-53.

31 Saukkonen JJ, Cohn DL, Jasmer RM, et al. An official ats statement: hepatotoxicity of antituberculosis therapy. Am J Respir Crit Care Med 2006;174:935-52.

32 Ferebee $\mathrm{SH}$. Controlled chemoprophylaxis trials in tuberculosis. A general review. Bibl Tuberc 1970;26:28-106.

33 Nolan CM, Elarth AM. Tuberculosis in a cohort of Southeast Asian refugees. A five-year surveillance study. Am Rev Respir Dis 1988;137:805-9.

34 Comstock GW. How much isoniazid is needed for prevention of tuberculosis among immunocompetent adults? Int $J$ Tuberc Lung Dis 1999;3:847-50.

35 Public Health Agency of Canada. Tuberculosis in Canada 2008. Government of Canada, 2009.

36 Public Health Agency of Canada. Tuberculosis in Canada 2009. Government of Canada, 2013.

37 Public Health Agency of Canada. Tuberculosis in Canada 2010 - Prerelease. Government of Canada, 2012.

38 Public Health Agency of Canada. Tuberculosis in Canada 2011 - PreRelease. Government of Canada, 2012.

39 Public Health Agency of Canada. Tuberculosis in Canada 2012. Government of Canada, 2014

40 Public Health Agency of Canada. Tuberculosis in Canada 2013 - Prerelease. Government of Canada, 2015

41 Public Health Agency of Canada. Tuberculosis in Canada 2014 - Prerelease. Government of Canada, 2016.

42 Gallant V, Duvvuri V, McGuire M. Tuberculosis in Canada - Summary 2015. Can Commun Dis Rep 2017;43:77-82.

43 Vachon J, Gallant V, Siu W. Tuberculosis in Canada, 2016. Can Commun Dis Rep 2018;44:75-81.

44 Bauer M, Leavens A, Schwartzman K. A systematic review and metaanalysis of the impact of tuberculosis on health-related quality of life. Qual Life Res 2013;22:2213-35.

45 Guo N, Marra F, Fitzgerald JM, et al. Impact of adverse drug reaction and predictivity of quality of life status in tuberculosis. Eur Respir $J$ 2010;36:206-8

46 Canadian Institute for Health Information. Care in Canadian ICUs [Internet]. CIHI, 2016. Available: https://secure.cihi.ca/free_products/ ICU_Report_EN.pdf 